\title{
The Fretting Fatigue Behavior of Ti-6Al-4V
}

\author{
R.W. Neu \\ The George W. Woodruff School of Mechanical Engineering and \\ School of Materials Science and Engineering \\ Georgia Institute of Technology \\ Atlanta, GA 30332-0405, USA \\ rick.neu@gatech.edu
}

Keywords: Crack Initiation, Crack Growth, Microstructure, Surface Treatments, Palliatives

\begin{abstract}
This paper reviews the understanding of fretting fatigue with an emphasis on the behavior of Ti-6Al-4V. Advances in life prediction and assessment approaches are highlighted. The role of microstructure on fretting fatigue and its use to detect fretting fatigue damage can now be considered in assessment strategies. Various palliatives are used to enhance the fretting fatigue resistance. These include treatments to introduce compressive residual stress and surface coatings that reduce friction and/or protect the underlying structural material.
\end{abstract}

\section{Introduction}

This paper reviews the tremendous progress over the past decade to understand and predict the fretting fatigue behavior of Ti-6Al-4V, a common alloy used in applications requiring high specific strength. Fretting fatigue is of particular concern for dovetail attachments between the blades and disks in compressors of aerospace gas turbines, spline couplings of shafts, and mechanical joints in orthopedic implants. In the past decade there has been considerable focus on the fretting fatigue behavior of the duplex microstructure consisting of 60 vol. \% equiaxed primary $\alpha$ (hcp structure) and 40 vol. $\%$ secondary lamellar $\alpha+\beta$ domains about 10 to $15 \mu \mathrm{m}$ in size composed of alternating lathes of $\alpha$ and bcc-structured $\beta$. This was the baseline microstructure used for several projects carried out under the Air Force High Cycle Fatigue (HCF) program from 1995 to 2005 [1,2]. Unless noted otherwise, the majority of the data reported in this review was generated on this or similar microstructure. The microstructure has an initial random texture with yield strength 930 $\mathrm{MPa}$, ultimate tensile strength $978 \mathrm{MPa}$, and cyclic yield strength of $797 \mathrm{MPa}$ [1].

The fretting fatigue process can be divided into two parts. The first is the formation of fretting cracks and the second is the growth of fretting fatigue cracks. The drivers for each of these processes are different. Both processes must occur to realize a catastrophic fretting fatigue failure. If fretting cracks do not form, fretting fatigue will not occur. But even if fretting cracks form, a catastrophic fretting fatigue failure will not occur if these cracks do not grow outside of the fretting fatigue process volume (FFPV) associated with the formation of the crack. Hence, the fretting fatigue limit is associated with the threshold limit for propagating the fretting cracks. In most fretting fatigue experiments and in applications, the drivers for fretting crack formation and crack growth outside of the FFPV cannot be easily separated, so there is an apparent coupling between the two. However, experiments involving the independent control of the drivers for fretting crack formation and crack growth (e.g., [3,4]) suggest that these two processes can be separated for the purposes of material response and prediction analyses. This is extremely helpful in understanding how different palliatives mitigate the fretting drivers. Some palliatives are aimed at fretting crack formation while others at reducing the fretting fatigue crack growth drivers. 


\section{Fretting Crack Formation}

The drivers for fretting crack formation can be understood through the use of fretting maps shown in Fig. 1. These maps relate the normal force and the displacement amplitude to the running condition and material response. The running condition is characterized by the tangential force displacement $(Q-\delta)$ hysteresis response that evolves as a function of cycles as the interface changes with fretting. Three primary regimes of running conditions can be identified: partial slip regime (PSR), mixed slip regime (MSR), and gross slip regime (GSR). The PSR represents conditions where part of the interface remains in stick for all cycles. Gross slip conditions, characterized by the horizontal parts of the $Q-\delta$ hysteresis loops, occur at larger displacement amplitudes. The MSR is characterized by initial gross slip that transitions to partial slip conditions with continued cycling, due to the increase in the coefficient of friction (COF) from the fretting damage in the slip regions.

The material response fretting map (MRFM) shown in Fig. 1 identifies the conditions that lead to fretting crack formation. The running conditions that lead to crack formation include MSR and PSR. In the PSR, the severity of fretting, quantified by the size of the fretting crack, increases with an increase in the $\delta_{a}$ and increase in size of the FFPV, which is related to the extent and magnitude
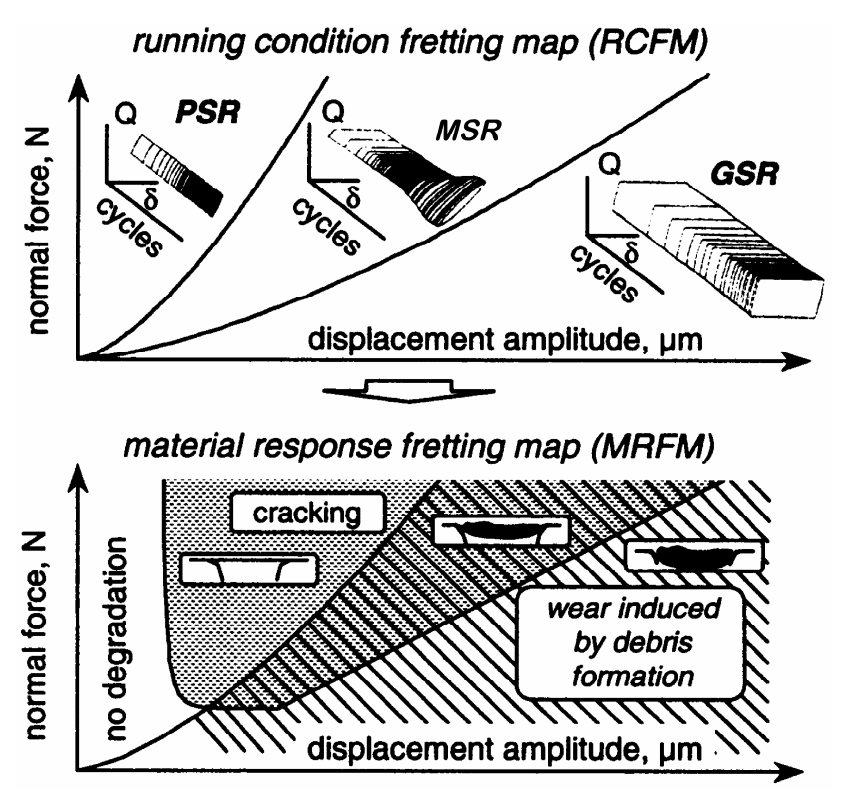

Fig. 1. Fretting maps [5]. of the fretting stresses. Alternatively, $Q_{a}$ can be interchanged with $\delta_{a}$ when operating in the PSR due to the linear relationship between $Q_{a}$ and $\delta_{a}$ in that regime. In the PSR, the normal force has a lesser effect than $\delta_{a}$ on crack formation (note the vertical transition boundary on the MRFM in Fig. 1) as long as the normal force is above a threshold related to the size of the FFPV [6].

The sizes of cracks formed in fretting of Ti$6 \mathrm{Al}-4 \mathrm{~V}$ on itself as a function of $\delta_{a}$ covering the three regimes for a constant normal force are shown in Fig. 2. The longest, worse-case cracks are generated in the MSR for dry contacts. Reported sizes range from 50 to $150 \mu \mathrm{m}[3,7-$ 10]. Near the transition between MSR and GSR, the fretting cracks reach their maximum size early in fretting cycling. In the PSR, the fretting cracks continue to grow after forming early as shown in Fig. 2(a).
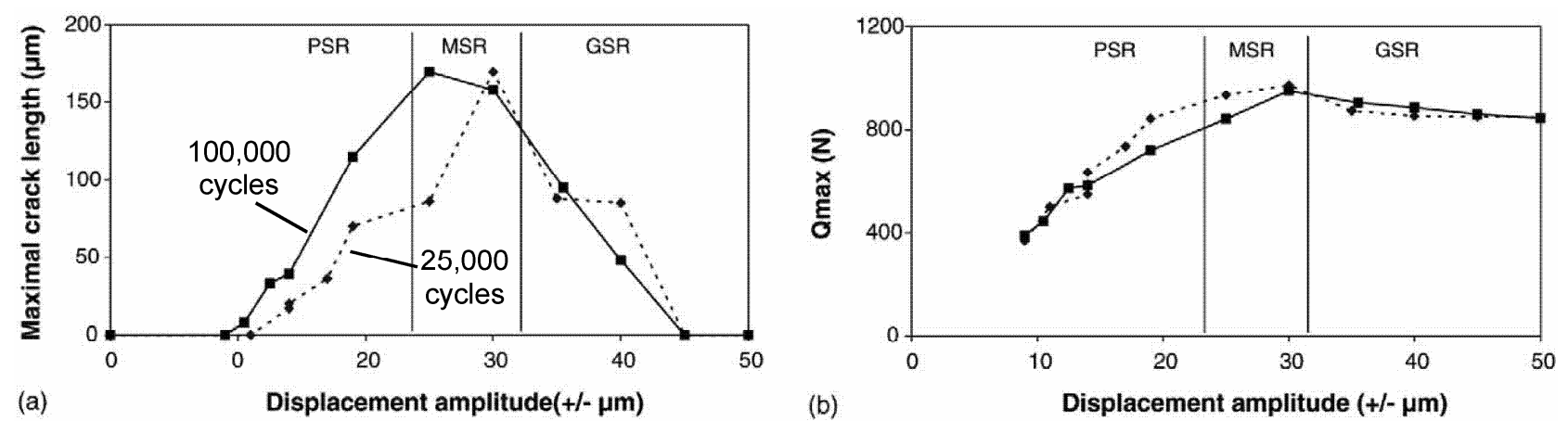

Fig. 2. (a) Maximum crack length and (b) maximum value of tangential force $Q_{\max }$ as a function of displacement amplitude for the fretting condition: Ti-6Al-4V on Ti-6Al-4V cylindrical contact with radius of $10 \mathrm{~mm}$ and width of $3 \mathrm{~mm}, P=1000 \mathrm{~N}\left(P / P_{y}=0.27\right)$ [7]. 
As the relative slip goes beyond the transition to gross slip, the fretting fatigue life increases because the fretting cracks that form are smaller [11-13]. This is attributed to the formation of wear particles that tend to prevent large cracks from forming [11,13]. In addition, wear expands the pressure and shear traction distributions at the interface effectively reducing the fretting stress concentration at the edge of contact $[11,12,14]$. Wear particles also tend to fill cracks leading to a reduction in fatigue crack growth driving force when there is some wear [15]. Wear particle formation itself is a fatigue process. Cracks tend to grow parallel to the surface in gross slip due to the tractions acting at the interface which tends to promote wear particle formation [16].

The bulk cyclic loading or residual stresses do not significantly affect the transition when these parameters are controlled independently [17]. For example, changing the phasing of the tangential force cycle and bulk fatigue stress cycle does not alter life if the bulk loading conditions and tangential force range are the same for different phasing [4]. This suggests that the material response associated with $Q_{a}$ can be decoupled from the bulk cyclic response. The $Q_{a}$ is a primary component of the driver for formation of the fretting cracks; the bulk fatigue stress is the main driver growing the fretting-initiated crack into the bulk. In the GSR, $Q_{a}$ is no longer a useful parameter to characterize the fretting damage since it does not change with $\delta_{a}$ yet the maximum fretting crack size is smaller with increasing $\delta_{a}$ (compare Figs. 2(a) and 2(b)).

\section{Predicting Fretting Crack Formation}

The driving force for crack formation is related to the cyclic stress-strain state in the FFPV near the interface of the two bodies. This cyclic stress-strain state depends on the interfacial pressure and shear tractions as well as any bulk cyclic loading. It also depends on the microstructure when the FFPV is the same size as critical microstructure attributes such as grain size [18-21]. For simple geometries such as cylinder-on-flat contacts and assuming linear elastic material behavior and a constant COF, these responses can be determined analytically [22,23]. For more complex twodimensional contact configurations including flat with blending radii and surfaces with roughness, semi-analytical approaches can be used provided the material remains nearly linear elastic (e.g., [24]) or the finite element method is used when the geometry and loading representing the attachment is complex and when nonlinear material models need to be considered. The difficulty with using the finite element method is the need for extreme mesh refinement or submodeling at the fretting hot-spot location. It is important to enforce stick and slip constraints along the interface to determine the local relative slip at the interface which is considerably smaller than what is measured at a remote point in a fretting fatigue experiment $[25,26]$.

These analyses typically show that the fretting hot spot is located near an edge of contact. Under conditions that promote fretting fatigue, this location is analogous to a sharp stress concentration [27,28]. Hence, characteristic of a sharp stress concentration, multiple cracks readily nucleate under cyclic loading [7,15,29-34]. Several criteria have been used to relate crack formation to the cyclic stress state [35]. Presently, critical plane multiaxial fatigue approaches that capture mean stress effects have the most general utility as fatigue parameters, particularly since the orientation of the fretting fatigue cracks depend on the cyclic stress-strain state. After the stabilized cyclic stress-strain response is determined in the body, the responses on different planes at potential hot spots are determined. Crack nucleation is then related to the magnitude of the fatigue parameter, often calibrated to smooth specimen data. For design, the relative magnitude of the fatigue parameter has utility as a performance metric.

Several critical plane multiaxial fatigue parameters have been considered for Ti-6Al-4V. Since shear cracking is promoted in the crack nucleation of Ti-6Al-4V, shear-based critical plane parameters, particularly ones that include a normal stress parameter to account for normal mean stress effects, tend to work the best in predicting the location and orientation of the crack as well as correlating cycles to failure based on smooth specimen data $[1,2,18,36-39]$. The two parameters that have exhibited the best success in correlating lives of Ti-6Al-4V include the FSK (FatemiSocie-Kurath) parameter $[40,41]$, 


$$
P_{F S K}=\frac{\Delta \gamma_{c r i t}}{2}\left(1+k \frac{\sigma_{\max }}{\sigma_{y}}\right)
$$

used by [35] for fretting fatigue (note that $k$ is typically unity for HCF though can be higher for LCF; Ref. [36] used $k=6.0$ for Ti-6Al-4V) and the modified shear stress range parameter, $P_{M S S R}$ $[18,39]$,

$$
P_{M S S R}=A \Delta \tau_{c r i t}^{B}+C \sigma_{\max }{ }^{D}
$$

where $\Delta \tau_{c r i t}$ is the shear stress range on the critical plane that is modified to account for the mean shear stress,

$$
\Delta \tau_{c r i t}=\tau_{\max }\left(1-\frac{\tau_{\min }}{\tau_{\max }}\right)^{m}
$$

and $\sigma_{\max }$ is the maximum normal stress acting on this plane at any point during the cycle. All planes at a point or averaged within a critical volume are evaluated and the one giving the largest value for $P_{M S S R}$ is the critical plane. For the duplex Ti-6Al-4V microstructure, the material parameters that have been shown to correlate the data are $m=0.45, A=0.75, B=0.5, C=0.75, D=$ 0.5 [18,39]. The $P_{M S S R}$ is essentially a generalization of the Findley critical plane model [42] that was found to correlate Ti-6Al-4V multiaxial plain fatigue data well $[1,2,36]$,

$$
P_{F}=\frac{\Delta \tau_{c r i t}}{2}+k \sigma_{\max }
$$

where $\sigma_{\max }$ is the maximum normal stress on the plane experiencing the maximum shear stress range. However, the Findley parameter did not predict the crack orientation in fretting fatigue $[18,39]$ using a $k$ of 0.35 based on the plain fatigue of Ti-6Al-4V $[1,36]$.

The Smith-Watson-Topper (SWT) parameter $P_{S W T}[43]$ has also been shown to be a successful fatigue parameter for Ti-6Al-4V [7,35,44,45]. It is defined by

$$
P_{S W T}=\sigma_{\max } \varepsilon_{a}=\frac{\left(\sigma_{f}^{\prime}\right)^{2}}{E}\left(2 N_{i}\right)^{2 b}+\sigma_{f}^{\prime} \varepsilon_{f}^{\prime}\left(2 N_{i}\right)^{b+c},
$$

where $\sigma_{\max }$ is the maximum normal stress on the critical plane at any point during the cycle and $\varepsilon_{a}$ is the strain amplitude on the same plane. The $P_{S W T}$ can be correlated to smooth specimen data for Ti-6Al-4V using modified Coffin-Manson parameters: $\sigma_{f}^{\prime}=2200 \mathrm{MPa}, b=-0.1260, \varepsilon^{\prime}=2.8, c=$ -0.86, and $E=120,400 \mathrm{MPa}$ [44]. This life fit was developed using uniaxial data from [1] and is valid for lives between 3000 and $10^{6}$ cycles including data with strain ratios ranging from $R=-1$ to 0.8. The threshold value of $P_{S W T}$ for long lives from $10^{6}$ up to $10^{8}$ cycles is $1.0 \mathrm{MPa}$. The $P_{S W T}$ is not always consistent in predicting the initial crack orientation $[2,18,39,46]$, which is inconsistent with a critical plane theory, though as the cracks grow away from the surface, the orientation often transitions to one consistent with $P_{S W T}$ [32]. 
The predictions using these critical-plane fatigue parameters based on the stresses at the critical hot spot point are almost always more conservative when lives are predicted based on smooth specimen data $[7,47,48]$. That is, the predicted knockdown is much more severe than fretting fatigue experiments exhibit. This is attributed to the severe gradient in the cyclic response near the hot spot point. Hence, analogous to notch analysis, the steep gradient in the response over a critical FFPV surrounding the fretting hot spot needs to be considered in the analysis either through some averaging scheme $[7,18,48-51]$ or critical distance [52]. The depth of this volume ranges from 10 to $50 \mu \mathrm{m}$ in typical attachment applications involving Ti-6Al-4V [6,7,50,51,53]. For example, based on the results shown in Fig. 2, the critical size of the FFPV is $30 \mu \mathrm{m}$ in the depth direction if the critical value for $P_{S W T}$ is $2.8 \mathrm{MPa}$, which represents 25,000 cycles to crack initiation based on Eq. (5) (see Fig. 3). The depth of this critical volume often relates to the maximum depth influenced by the fretting stresses. An alternative approach for capturing the hot spot volume for determining fretting crack nucleation in the PSR involves using an asymptotic approach to determine the intensity of the stresses at the edge of contact [33,53-57]. In this approach either the intensity of the singularity in the stress field near the edge of contact is correlated to crack nucleation or the singular stress field is used to determine the driving force for cracks emanating from the edge of contact.

In reality, the mechanism for crack nucleation in fretting fatigue is likely related to ratcheting, a localized progression of plastic strain in one direction. Ratcheting is observed experimentally [31] and is promoted in modeling when the influence of microstructure in the deformation field is captured, which requires microstructure-based plasticity models [19-21]. Conventional elasticplastic models based on $\mathrm{J}_{2}$ plasticity cannot capture the level of localized ratcheting in heterogeneous microstructures, hence employing a ratcheting parameter will not be fruitful unless a comprehensive microstructure-based plasticity is used. As the physics of the deformation process is captured better in the future, a ratcheting-based criteria, typically related to ductility exhaustion [58], will likely be more appropriate for determining crack formation. Ratcheting is a shear-based phenomena that likely is affected by the normal stress on the maximum shear plane. The $P_{F S K}$ and $P_{M S S R}$ involve the same parameters that will relate to ratcheting, so it is not surprising that these parameters tend to work well.

The local fretting stresses and hence the fretting damage prediction (i.e., the magnitude of the fatigue parameter) strongly depend on the COF [59-61]. Hence, the choice of the COF used in fretting fatigue analyses is critical. Friction in the slip regions usually increases significantly during fretting, typically during the early stages. This is attributed to (a) the removal of the passivation

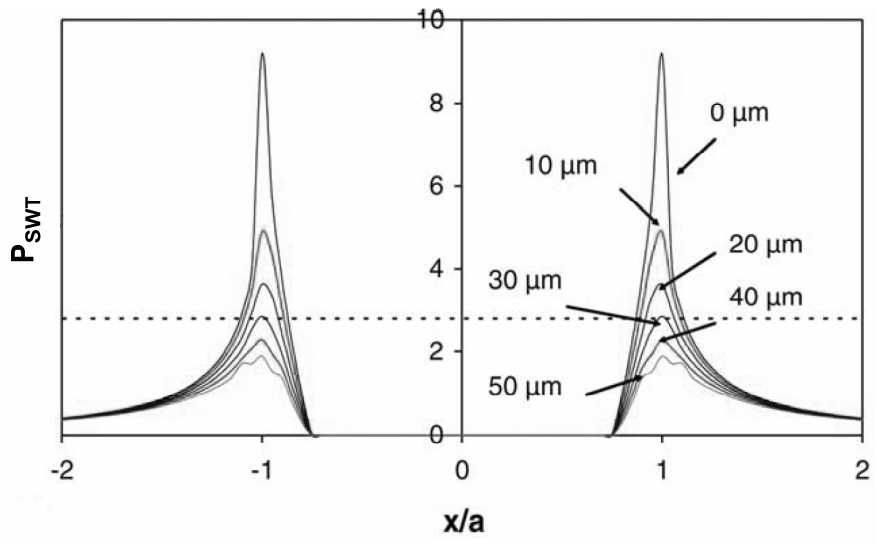

Fig. 3. Distribution of $P_{S W T}$ in the surface layer as a function of position for different sizes of the FFPV for the following fretting and analysis conditions: Ti-6Al-4V on Ti-6Al-4V cylindrical contact with radius of $10 \mathrm{~mm}$ and width of $3 \mathrm{~mm}, P=1000 \mathrm{~N}$, $Q_{\max }=520 \mathrm{~N}, \mathrm{COF}=0.9[7]$. layer leading to metal on metal contact and local adhesion or instantaneous welding of asperities, (b) the increase in the real contact area due to the wear of the highest asperities, and (c) build-up of material, a plunging effect, that provides additional tangential force resistance, particularly important near gross slip conditions [51]. For fretting of Ti-6Al-4V on itself or another $\mathrm{Ti}$ alloy, the reported steady-state COF measured in experiments ranges from 0.5 to $1.5[1,7,11,16,51,62-64]$. It needs to be kept in mind that these measured values are still an aggregate measure representing the average response over the region undergoing slip assuming the entire interface is in contact. In reality the real area of contact is considerably smaller than the area of contact and hence locally, the 
effective COF is greater than these measured values and does not remain constant $[59,61,64]$. This can explain some of the large variability in the measured values. Since it is the local response that controls crack nucleation, higher values of COF are usually needed to better correlate the response. The use of $\mathrm{COF}=0.9$ or greater for uncoated dry Ti-6Al-4V on Ti alloy contacts seems to give response distributions that are consistent with experiments $[7,61,65,66]$.

\section{Fretting Fatigue Limit and Crack Growth}

The relationship between plain fatigue strength for $10^{7}$ cycles and fretting fatigue strength as a function of stress ratio $\mathrm{R}$ is shown in Fig. 4. The worse-case fretting fatigue limit for Ti-6Al-4V is based on the model of Chan et al. [67,68] for mean pressure of $200 \mathrm{MPa}$. The worse-case fretting fatigue limit is only realized if fretting cracks of sufficient size have formed. The relationship between fretting crack size and its effect on the fretting fatigue strength can be understood using a Kitagawa-Takahashi type diagram as shown in Fig. 5 [66]. Fretting cracks that do not grow larger than $50 \mu \mathrm{m}$ due to fretting stresses will become non-propagating if the bulk fatigue loading is below the worse-case fretting fatigue limit. The largest cracks form when the fretting conditions are operating in the MSR (Fig. 2) near the transition between partial and gross slip, when $Q_{a}$ is approaching the maximum value of $\mu P$ where $\mu$ is the COF. The UTRC data shown in Fig. 4 corresponds to gross slip conditions. With less severe fretting conditions, the fretting fatigue limit is higher than the worse-case curve. For example, the fretting fatigue limits of Lovrich and Neu [33], particularly at higher $R$, correspond to a PSR condition well below the transition to gross slip $\left(Q_{d} / P=0.3\right.$ to 0.5$)$. In these cases, the realized fretting fatigue strength curve is above the worsecase curve. For fully-reversed loading $R=-1$, the fretting fatigue running condition is approaching gross slip due to the higher amplitude of loading. Hence, the fretting fatigue limit for $R=-1$ is near the worse-case threshold.

Between the fretting fatigue and plain fatigue limit is the finite life fretting fatigue regime. Several models have been proposed to determine the drivers in the finite life regime. The worsecase lower limit can be raised via modification of the fretting stresses and through the use of palliatives discussed later.

Since cracks form readily under conditions that promote fretting as discussed in the previous

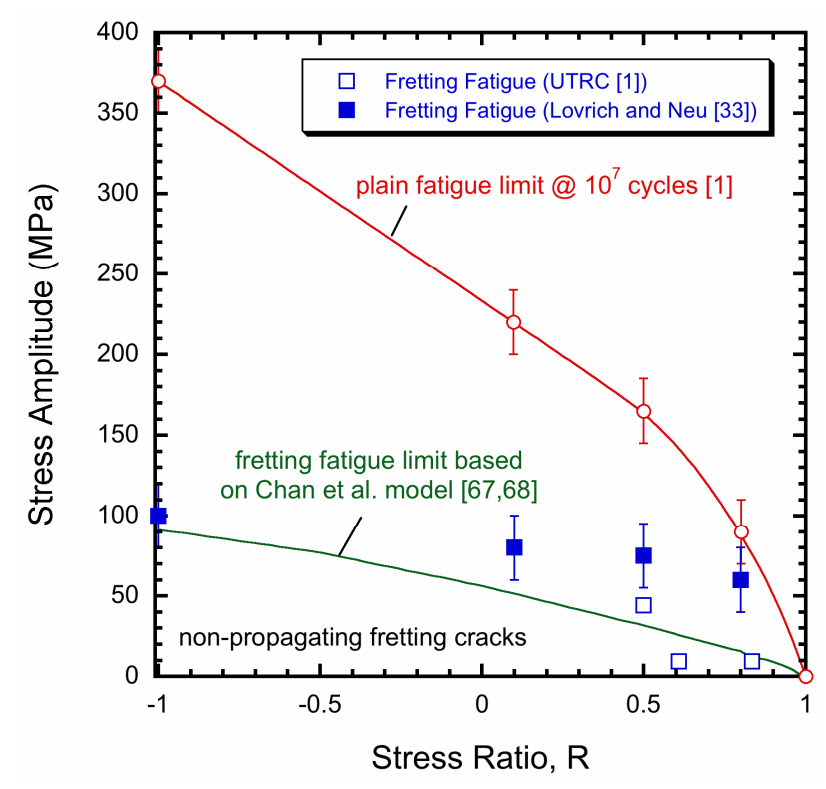

Fig. 4. Influence of bulk stress amplitude and stress ratio on the fretting fatigue limit based on $10^{7}$ cycles.

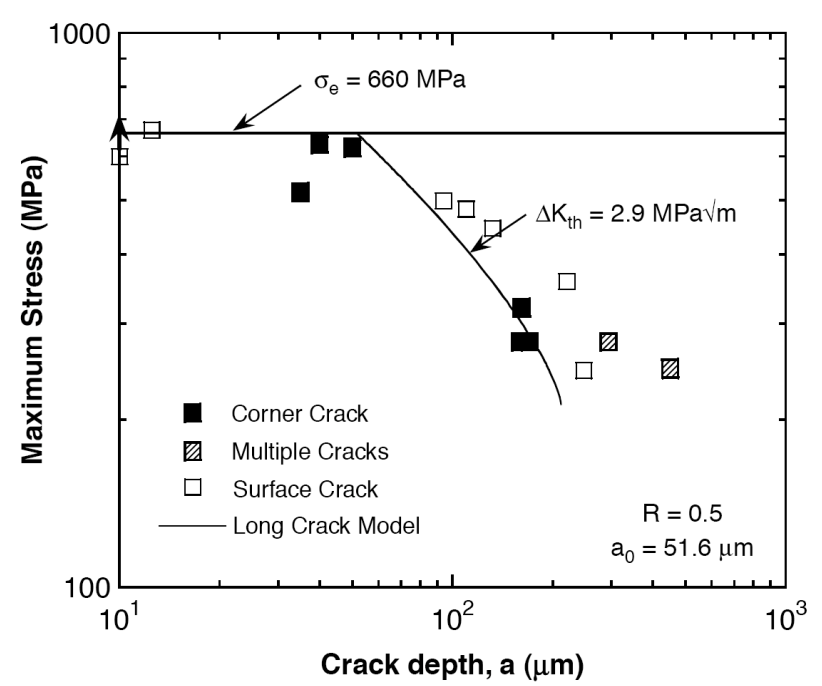

Fig. 5. Kitagawa-Takahashi type representation of residual fatigue strength for fretting-fatigue damaged Ti-6Al-4V specimens exhibiting cracks [66]. 
section, a fretting crack is assumed to be present and a fracture mechanics approach is used to determine the fretting fatigue limit (e.g., [3,65,67]). The initial crack size is either arbitrarily chosen based on minimum crack size that can be detected using nondestructive inspections or determined by the critical size of the FFPV determined in a crack initiation analysis [56,69]. A long crack growth model for duplex Ti-6Al-4V was developed in the U.S. Air Force HCF program $[1,53]$. A combined initiation and crack growth approach often offers more success in the finite life fretting regime $[3,24,56,69]$. Hence, as long as the cracks that form from fretting remain smaller than the critical flaw size, determined by the crack driving force $\Delta K$ being less than the threshold $\Delta K_{t h}$, the structure is safe. For duplex Ti-6Al-4V, the worst-case "closure-free" threshold $\Delta K_{t h}=$ 1.9 $\mathrm{MPa} \mathrm{m}^{1 / 2}$ [70]. This value is determined from a $R=0.95$ test. As the stress ratio $R$ decreases, the threshold increases to $\Delta K_{t h}=2.9 \mathrm{MPa} \mathrm{m}^{1 / 2}$ for $R=0.5$ and $\Delta K_{t h}=4.6 \mathrm{MPa} \mathrm{m}^{1 / 2}$ for $R=0.1$ [70]. The difficulty of using this approach is determining $\Delta K$ for small cracks while including the fretting stresses. There is a need to consider mixed-mode crack drivers as well as corrections for small cracks [3,57,67-69,71], particularly microstructurally-short cracks [72].

\section{Effect of Microstructure}

Ti-6Al-4V can be processed and heat-treated to produce a variety of microstructures having considerable differences in fatigue properties [73]. Systematic variations in microstructure on fretting fatigue strength were considered by [16] for fretting fatigue in point contact with $P / P_{y}<$ 0.10. Microstructures considered included mill-annealed, solution-treated and overaged (STOA), acicular, Widmanstätten, and a highly hardened martensitic. It should be noted that the pointcontact configuration produced rather mild fretting fatigue conditions compared to other studies involving line contacts; i.e., the fretting fatigue strength of the baseline microstructure was about $225 \mathrm{MPa}$ at $R=-1$, which is considerably greater than the worse-case fretting fatigue strength (see Fig. 4). Under these conditions, the microstructure did not significantly influence the fretting fatigue behavior except in the case of the highly hardened martensitic microstructure which had a yield strength of $1137 \mathrm{MPa}$ and greater fretting fatigue resistance compared to all the other microstructures which had yield strengths ranging from 850 to $970 \mathrm{MPa}$. Hence, fretting fatigue lives scale with hardness and yield strength. In addition, a coarse STOA exhibited a lower fretting fatigue strength compared to the baseline STOA, though the difference was not more than a factor of two. This trend is consistent with fretting crack nucleation predictions that employ microstructure-based modeling [74].

In another study a homogeneous bi-modal microstructure (i.e., the duplex microstructure) was shown to have better fretting fatigue crack nucleation resistance than a heterogeneous lamellar microstructure [75]. This is consistent with plain fatigue trends for crack nucleation and is opposite the long crack growth behavior where a heterogeneous lamellar microstructure tends to provide more resistance to crack growth due to the increased torturous nature of the crack path [76]. Hence, a microstructure that is more resistant to fatigue crack nucleation will also likely be more resistant to fretting crack formation.

Deformation processes can create crystallographic texture in the microstructure. Texture is known to affect the cyclic response and fatigue life of Ti-6Al-4V in ordinary fatigue [77]. This is attributed to cracks nucleating via quasi-cleavage along basal planes of the $\alpha$ nodules. Dislocation slip mainly occurs in the primary $\alpha$ nodules along prismatic and basal planes with the largest Schmid factors [78]. Hence, the location of these primary $\alpha$ nodules with respect to the fretting stresses is critical. The influence of these microstructure attributes on fretting crack formation and crack growth can be determined using three-dimensional microstructure-based modeling $[21,74,79$ 81]. Recent crystal plasticity models for Ti-6Al-4V [82] are able to capture the influence of crystal orientations of both primary $\alpha$ and $\alpha+\beta$ lamellar colonies by considering the distinct threedimensional slip geometry for each phase. These modeling studies clearly show that the localized cyclic deformation, which is the driver for crack formation, is quite dependent on the heterogeneity of the microstructure. The difference in the deformation response of adjacent domains results in the highly localized cyclic shear near the boundaries between these domains. 


\section{Effect of Environment}

When fretting fatigue tests are conducted in air, the fretting fatigue behavior of Ti-6Al-4V is insensitive to temperature unless it is greater than $400^{\circ} \mathrm{C}$ [10,83-85]. At very high temperatures $\left(>400^{\circ} \mathrm{C}\right)$, a glaze oxide may form which tends to reduce friction and help protect the surface, leading to reduce wear and an increase in life [86]. Any corrosive process that causes a layer to form on the surface tends to be protective and hence beneficial [87].

Even air may be considered a corrosive environment for Ti alloys. Fatigue tests conducted in vacuum compared to air generally have a considerably greater fatigue life. Quasi-cleavage along basal planes occurs in air atmosphere, perhaps due to hydrogen [88]. The influence on fretting fatigue in vacuum or inert environments may be different due to the increased adhesion and reduction of abrasive wear that occurs in a reduced oxygen environment. In addition, increased oxygen levels in the FFPV will locally reduce the ductility, fracture toughness, stress-corrosion resistance, and fatigue crack growth resistance of Ti-6Al-4V [73]. However, no studies have been reported that systematically address the influence of reduced oxygen on fretting fatigue behavior of Ti-6Al-4V. When fretting fatigue experiments are conducted in simulated seawater environment, the life is reduced $[89,90]$.

\section{Changes in Surface Characteristics with Fretting}

Fretting increases the oxygen in the surface layers including formation of oxides, primarily TiO and $\mathrm{TiO}_{2}[8,91,92]$. Fretting also has been shown to produce a basal microtexture in the surface layer to a depth of about $20 \mu \mathrm{m}$ [92,93]. In slip regimes a finer transformed microstructure has been observed [91,94,95] including transformation of $\beta$ into $\alpha$ [91]. An increase in hardness of the surface layer is generally associated with these changes in the surface structure and with an increase in oxygen $[91,92,94,95]$. Fretting damage generated in gross slip conditions exhibit more obvious changes (cf. $[94,96]$ ), though similar changes have been observed in the microslip regions under partial slip conditions.

Since there is plastic deformation in the surface layer particularly near the slip regions along the interface [97], an increase in low angle misorientations occurs and can be measured using electron backscatter diffraction (EBSD) techniques [92,93]. The magnitude of the misorientations depends on the relative slip amplitude and number of cycles [93]. Residual stresses also develop in the surface layer, initially free of residual stresses, due to the constrained cyclic plasticity $[98,99]$. Though in cases where the deformation is localized very near the edge of contact, residual stresses are generally difficult to detect [100].

An increase in surface roughness leads to increased pressure where asperities contact, often promoting crack nucleation due to adhesion at asperities and intense pressures [101], but since the fretting fatigue process volume tends to be smaller because of the steeper gradient in the stressstrain field, a decrease in fretting fatigue life is not always realized and in many cases there can be a benefit with increased roughness as discussed in the next section.

The effect of different pad materials (e.g., Al alloy, Inconel) does not significantly change the fretting fatigue life of Ti-6Al-4V if the fretting stresses in the Ti-6Al-4V body are equivalent [38,102]. Though different materials can certainly modify these fretting stresses because of the difference in material properties, friction, and wear behavior.

\section{Surface Treatments}

There are five functional categories of surface treatment strategies for fretting fatigue. All have been used to improve the fretting fatigue behavior of Ti-6Al-4V. Effective palliatives shift the fretting fatigue strength up from the worse-case fretting scenario (refer to Fig. 4).

(1) Induce compressive residual stress in the surface layer via a mechanical treatment. This works by arresting cracks that have formed from fretting and hence its function is to reduce the driver for fatigue crack growth. 
(2) Decrease friction (for displacement control fretting conditions). Its function is the reduction of the cyclic fretting stresses, and hence its primary effect is reducing the driving forces for fretting crack formation.

(3) Increase hardness. Increasing hardness reduces the extent of plasticity in the surface layer, which is a significant driver for forming fretting cracks. In addition, relaxation of compressive residual stresses due to cyclic plasticity will be minimized. Hence, the primary function is to increase the material resistance to fretting crack formation.

(4) Increase shear compliance between bodies (e.g., via "softer" coating with lower modulus and/or yield strength). This works by enabling the relative displacement to be localized in the compliant layer reducing the fretting stresses in the structural substrate material. Thicker coatings or shims tend to be more effective since a larger shear displacement can be accommodated. The primary effect is a decrease in the driver for fretting crack formation.

(5) Increase surface roughness (i.e., textured surface). Tailoring the surface topography tends to reduce the effective FFPV and reduce the localized stress concentrations due to fretting, both of which decrease the driver for fretting crack formation [103,104]. Increasing the surface roughness is most effective when it is coupled with an increase in hardness so the textured surface will not be worn away in the slip regions.

Surface treatments are only effective if their function does not degrade under fretting conditions. Residual stresses relax, coatings wear away, surface roughness evolves with wear, friction increases, and so on.

Mechanical Treatments - Compressive Residual Stress. Since the fretting fatigue limit is associated with the arrest of small cracks generated from the cyclic shear at the interface, introducing compressive residual stress at the locations of the anticipated crack tips of the fretting cracks is quite effective in increasing the fretting fatigue limit. Inducing compressive residual stress is highly effective as long as the depth of the compressive residual stresses is greater than the depth of the cyclic fretting stress field (i.e., the FFPV).

Processes that induce compressive residual stress also typically increase the hardness of the surface layer, which generally has a beneficial effect since it reduces the extent of cyclic plasticity near the surface. The most common processes include shot peening [105-112], laser shock peening (LSP) [110,111,113], and low plasticity burnishing (LPB), also known as deep rolling [34,108,111,113,114]. Both LSP and LPB generate considerably deeper compressive residual stresses while inducing less cold work compared to shot peening. The main concern with any of these treatments is ensuring that the self-equilibrating tensile residual stresses are not located in a highly stressed region where cracks can form [34,107,112]. LPB needs to be carefully controlled to prevent any change in surface profile that may acerbate fretting [34]. Cavitation shotless peening [115] is another process though it presently does not appear to generate sufficiently deep residual stresses for significant benefit in fretting. It is possible to capture the influence of residual stresses on the fretting fatigue driving force using finite element analysis [107,116,117].

Another concern is the relaxation of residual stresses. This can be due to plasticity in surface layers $[85,98,99,109,111,118,119]$ or due to elevated service temperature $[85,106,120]$. For example, about $30 \%$ of the residual stresses generated by shot peening relaxed during a test at $260^{\circ} \mathrm{C}$, resulting in a reduction in fretting fatigue life [85]. LSP- and LPB-generated residual stresses do not relax as readily due to the deeper compressive stress and the reduction in cold work. Excessive cold work accelerates the relaxation of residual stresses [112]. It is possible to recover the residual stresses by reshot peening as long as critical fretting cracks have not already formed [121]. 
The effect of different process treatments on fretting fatigue life is shown in Fig. 6. These specimens were soaked at $375^{\circ} \mathrm{C}$ for 10 hours after treatment to replicate the relaxation due to inservice temperatures. A significant benefit remained even for shot-peened specimens compared to the untreated case in this study. Note that LPB can even provide equivalent or longer life than plain fatigue under loading conditions such as bending where the largest cyclic stress is restricted to the compressive residual stress volume.

To underscore that the function of surface treatments generating deep compressive residual stresses is to reduce the crack growth driving force, fretting fatigue cracks formed in a LPB-processed specimen are shown in Fig. 7. Without treatment, the life is less than 50,000 cycles [33]. The cracking behavior is typical of a severe fretting condition. Multiple cracks form, generally at an angle related to the cyclic fretting stress-strain field. These cracks arrested in the compressive field, in this case, nearly $200 \mu \mathrm{m}$ deep. Also note that oxide debris often fills the cracks that form, reducing the stress intensity range at the crack tips. Because of the multiple cracks, shielding effects also reduce the crack growth driving force. The wide mouths of the fretting cracks indicate that ratcheting of plastic strain is an

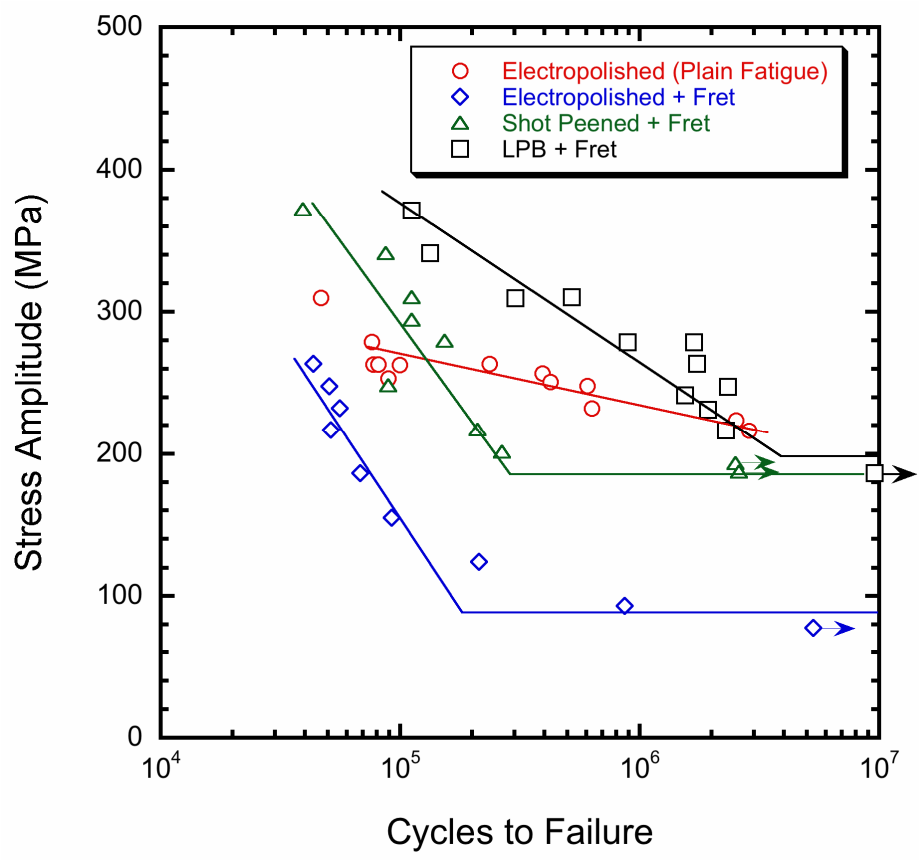

Fig. 6. Fretting fatigue life data for Ti-6Al-4V in 4-point bending comparing three different surface treatments: electropolished, shot peened, and LPB for $R=0.1$ tested at room temperature at $30 \mathrm{~Hz}$ after a 10 hour soak at $375^{\circ} \mathrm{C}[108,112]$.

important driver for fretting crack
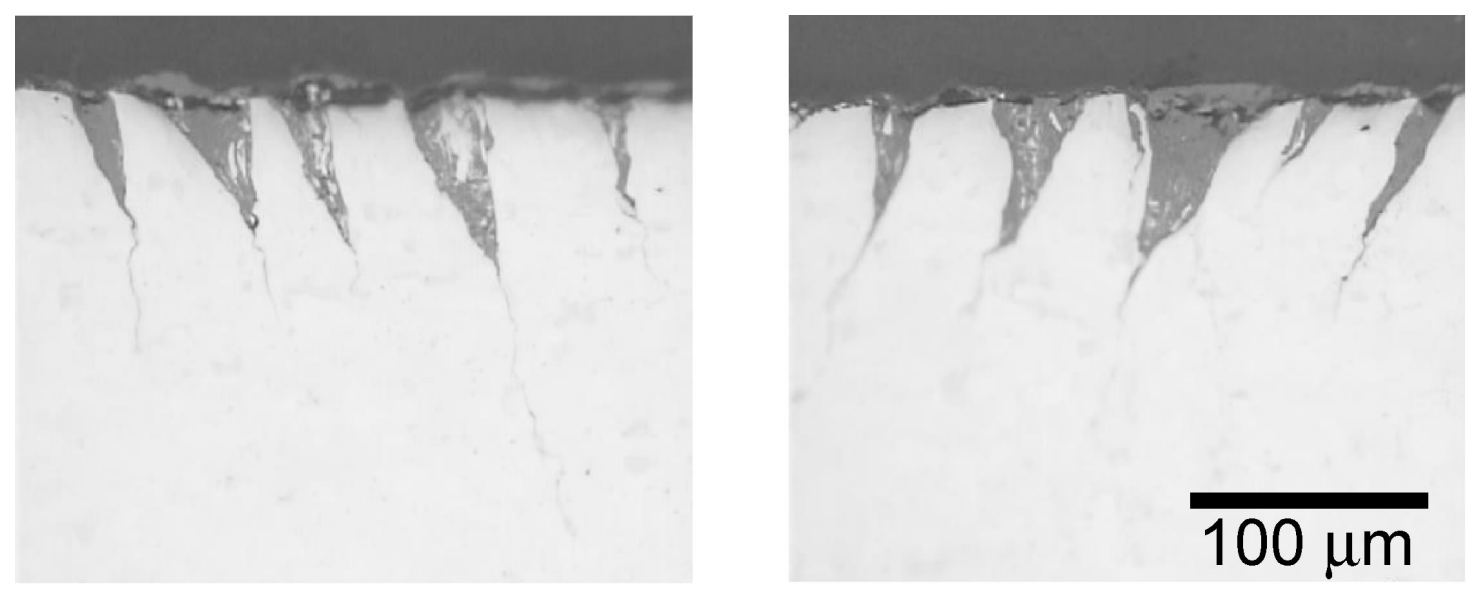

Fig. 7. Optical microscope images of a cross section showing the cracks in a LPB specimen near each edge of a cylindrical Ti-6Al-4V on Ti-6Al-4V contact with radius of $50 \mathrm{~mm}$ and width (perpendicular to the fretting direction) approximately $3.2 \mathrm{~mm}$ tested at $\sigma_{a}=$ $275 \mathrm{MPa}, R=-1, P=1340 \mathrm{~N}$ for 528,000 cycles [34]. 
formation [31]. Because the compressive residual stresses reduce the crack growth driving force, the maximum crack size formed from the fretting stresses alone is smaller when a compressive residual stress is present as shown in Fig. 8.

Coatings and Diffusion Treatments. An effective coating satisfies multiple objectives of surface treatments. Most are aimed at minimizing fretting fatigue crack formation by eliminating it completely or reducing the drivers so the resulting fretting cracks are smaller (i.e., the FFPV is reduced). Due to the proprietary nature

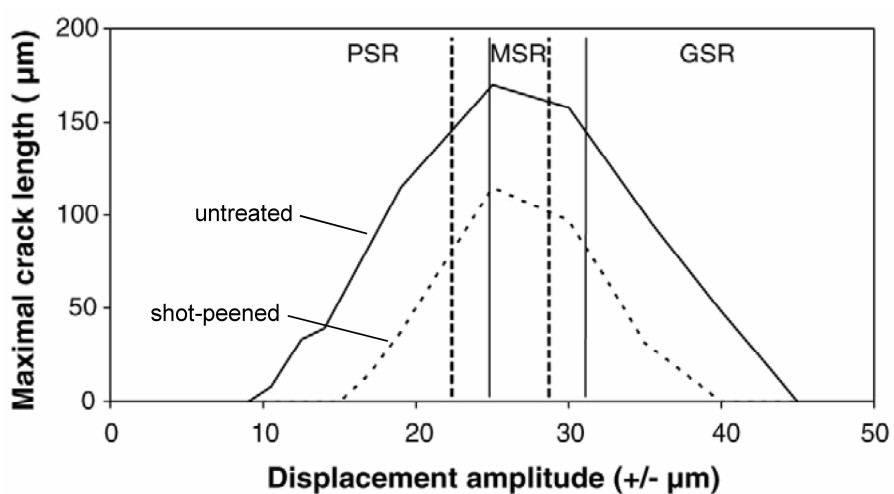

Fig. 8. Maximum crack size after 100,000 cycles from fretting alone, comparing untreated and shotpeened surfaces [7].

of coating systems, an exhaustive review is not possible. Hence, the focus here will be on some of the more common coatings where its effect on fretting of Ti-6Al-4V has been documented. It should be kept in mind that most coatings have been evaluated under a limited range of fretting conditions and under particular processing conditions. Hence, results at times are conflicting and are only beneficial, if indeed the case, under those particular conditions.

Surface treatments that permanently reduce friction generally improve the fretting fatigue life. Lower friction reduces the volume of material undergoing large cyclic fretting stresses and therefore reduces the FFPV. Coatings can be separated into three main categories: hard metallicbased coatings, soft coatings, and non-metallic coatings.

Hard metallic-based coatings: The typical characteristics of hard coatings include a hardened surface, usually lower COF, and often the added benefit of compressive residual stress in the surface layer. One example of hard coatings is ion implantation of N, C, or B [122-127]. The strengthening mechanism involves both solution and precipitate hardening. Generally, the latter (i.e., TiN precipitation or carbide formation) is required to show a significant improvement in fretting fatigue and wear behavior. TiN particles do not readily form in Ti-6Al-4V because $\mathrm{N}$ has good solubility in $\alpha$-Ti [124]. For ion implantation, the depth of penetration is typically less than $0.5 \mu \mathrm{m}$ [124]. Ion implantation results on Ti-6Al-4V to date do not show significant improvement particularly for attachment applications involving metal-on-metal contact and a FFPV larger than $0.5 \mu \mathrm{m}$. This technique seems to have more success in orthopedic implants when the contacting body is a polymer. Plasma nitriding generally gives a deeper case (e.g., $4 \mu \mathrm{m})[111,126,128]$. However, the COF can also increase resulting in a reduced fretting fatigue strength [111]. To get deeper cases, the processing temperature needs to be higher, which can adversely affect the base Ti6Al-4V microstructure. Plasma nitriding appears to be better than PVD TiN coatings which degrade in the microslip regions due to delamination and abrasive wear damage [126,128,129]. Ion-beam-enhanced deposition (IBED) of CrN films provides reduction in COF, high hardness, and compressive stress in the surface layer and hence may be beneficial [130]. The thickness of the film is about $1 \mu \mathrm{m}$ though the hardening depth of IBED films is deeper than the film thickness due to the effect of ion beam bombardment [130].

Soft coatings: The function of soft coatings is to increase the shear compliance between the bodies and usually lower the COF. These coatings tend to be much thicker than typical hard metallic-based coatings, often 50 to $150 \mu \mathrm{m}$ thick. These coatings tend to reduce the local fretting stresses [131], perhaps in part due to a favorable pressure and traction redistribution. In addition, the reduced elastic modulus of the coating coupled with the thickness results in an increase in the shear compliance at the interface, thus the term "soft" coating. A common example for Ti-6Al-4V is plasma spray $\mathrm{Cu}-\mathrm{Al}$ coatings, sometimes called Al-bronze coatings [114,131-134]. The composition is typically about $90 \% \mathrm{Cu}$ and $10 \% \mathrm{Al}$ plus some other elemental additions. The elastic modulus is closer to $50 \mathrm{GPa}$ versus the base Ti-6Al-4V value of $120 \mathrm{GPa}$. Under fretting wear conditions, the wear of this coating scales with dissipated energy (i.e., size of the hysteresis 
loops) [134,135]. Results on improving fretting fatigue have been mixed [132,133]. Plasma spray $\mathrm{Cu}-\mathrm{Ni}$ have been shown to lower $\mathrm{COF}$ and increase roughness which becomes smoother with fretting, likely prolonging life due to traction redistribution [136,137]. Other thick soft coatings such as plasma spray Mo (40 $\mu \mathrm{m}$ thick) and electroless Ni-B $(55 \mu \mathrm{m}$ thick) result in some reduction in friction and wear, though they show evidence of little improvement on the fretting fatigue behavior [111]. Electroless $\mathrm{Ni}-\mathrm{B}$ coating reduces wear, attributed to the increased hardness due to the boron addition, yet there is little improvement on fretting fatigue life.

Non-metallic coatings: The function of non-metallic coatings is to decrease the COF and usually increase hardness of the surface. An example is diamond-like carbon (DLC) coatings. The typical thickness of these coatings is 1 to $5 \mu \mathrm{m}$. These coatings show some promise particularly under milder fretting conditions in the partial slip regime for which the coating will not become damaged $[111,113]$. The primary mechanism leading to the improvement in life is the reduction in the COF, for example, from 0.7 to 0.25 in one study [113]. Under more severe fretting conditions including gross slip and higher load fretting conditions, these coatings may wear away or delaminate.

\section{Future Directions}

Compared to most material systems, there is a good amount of fretting fatigue data coupled with microstructure-based models for duplex Ti-6Al-4V. Hence, this is an ideal system to evaluate new microstructure-based design approaches with the objective of developing process routes that result in robust surface microstructures for better fretting fatigue performance. Through a computational materials design approach, one could conceivably include process-structure models of surface treatments, coupled with fretting fatigue microstructure-performance models in designing robust surfaces that are resistant to fretting fatigue.

Surface treatments are only effective if the depth of property changes is congruent with the fretting loading conditions; hence, a computational materials design solution that takes into account the variation in material microstructure with depth, the distribution of residual stresses, along with the geometry and loading of the two bodies in contact is needed. The evolution of the microstructure and residual stresses can be an important component of the fretting crack formation process.

New techniques to characterize fretting damage will be critical in validating these microstructure-based approaches. The latest include quantifying the relationship between the threedimensional microstructure and fretting cracks via serial sectioning using either conventional metallographic approaches or focused ion beam (FIB), and X-ray micro-tomography coupled with a crystal microscope [138].

\section{Acknowledgements}

This work was sponsored (in part) by the Air Force Office of Scientific Research, under grant no. FA9550-04-1-0418. The views and conclusions contained herein are those of the authors and should not be interpreted as necessarily representing the official policies or endorsements, either expressed or implied, of the Air Force Office of Scientific Research or the U.S. Government.

\section{References}

[1] J.P. Gallagher et al.: Improved High-Cycle Fatigue (HCF) Life Prediction, Final Report for December 1996 - December 1999, AFRL-ML-WP-TR-2001-4159 (2001).

[2] J.P. Gallagher et al.: Advanced High Cycle Fatigue (HCF) Life Assurance Methodologies, Final Report for April 1999 - July 2004, AFRL-ML-WP-TR-2005-4102 (2005)

[3] P.J. Golden and A.F. Grandt, Jr.: Engng Fract. Mech., Vol. 71 (2004), p. 2229.

[4] H. Lee and S. Mall: J. Engng Mater. Technol., Vol. 128 (2006), p. 202. 
[5] S. Fouvry, P. Kapsa and L. Vincent, in: Fretting Fatigue: Advances in Basic Understanding and Applications, ASTM STP 1425, edited by Y. Mutoh, S.E. Kinyon and D.W. Hoeppner, ASTM International, West Conshohocken, PA (2003), p. 17.

[6] J.A. Araujo and D. Nowell: Int. J. Fatigue, Vol. 24 (2002), p. 763.

[7] V. Fridrici, S. Fouvry, P. Kapsa and P. Perruchaut: Wear, Vol. 259 (2005), p. 300.

[8] W.A. Glaeser and B.H. Lawless: Wear, Vol. 250 (2001), p. 621.

[9] S. Fouvry, K. Elleuch and G. Simeon: J. Strain Anal., Vol. 37 (2002), p. 549.

[10] X. Huang and R.W. Neu: submitted to Wear (2006).

[11] S. Malkin, D.P. Majors and T.H. Courtney: Wear, Vol. 22 (1972), p. 235.

[12] O. Jin and S. Mall: Int. J. Fatigue, Vol. 24 (2002), p. 1243.

[13] R. Magaziner, O. Jin and S. Mall: Wear, Vol. 257 (2004), p. 190.

[14] J.J. Madge, S.B. Leen, I.R. McColl and P.H. Shipway: Wear, Vol. 262 (2007), p. 1159.

[15] B.P. Conner, A.L. Hutson and L. Chambon: Wear, Vol. 255 (2003), p. 259.

[16] T.A. Venkatesh, B.P. Conner, C.S. Lee, A.E. Giannakopoulos, T.C. Lindley and S. Suresh: Met. Mater. Trans. A, Vol. 32A (2001), p. 1131.

[17] H. Lee and S. Mall: Wear, Vol. 260 (2006), p. 642.

[18] S.A. Namjoshi, S. Mall, V.K. Jain and O. Jin: J. Strain Anal., Vol. 37 (2002), p. 535.

[19] C.-H. Goh, J.M. Wallace, R.W. Neu and D.L. McDowell: Int. J. Fatigue, Vol. 23 Supplement 1 (2001), p. S423.

[20] C.-H. Goh, D.L. McDowell and R.W. Neu: J. Mech. Phys. Solids, Vol. 54 (2006), p. 340.

[21] J.R. Mayeur, D.L. McDowell and R.W. Neu: Comp. Mater. Sci. (2007), in press.

[22] D. Nowell and D.A. Hills: Int. J. Mech. Sci., Vol. 29 (1987), p. 355.

[23] D.A. Hills and D. Nowell: Mechanics of Fretting Fatigue (Kluwer Academic Publishers 1994).

[24] B.B. Bartha, T. Nicholas and T.N. Farris: Tribol. Int., Vol. 39 (2006), p. 1131.

[25] C.-H. Goh, R.W. Neu and D.L. McDowell, in: Fretting Fatigue: Advances in Basic Understanding and Applications, ASTM STP 1425, edited by Y. Mutoh, S.E. Kinyon and D.W. Hoeppner, ASTM International, West Conshohocken, PA (2003), p. 183.

[26] V. Sabelkin and S. Mall: Fatigue Fract. Engng Mater. Struct., Vol. 28 (2005), p. 809.

[27] Y. Mutoh: Int. J. JSME, Series A, Vol. (1995), p. 405.

[28] D. Nowell and D. Dini: Tribol. Int., Vol. 36 (2003), p. 71.

[29] D.W. Hoeppner and G.L. Goss: Wear, Vol. 27 (1974), p. 175.

[30] R.A. Antoniou and T.C. Radtke: Mater. Sci. Engng, Vol. A237 (1997), p. 229.

[31] J.M. Wallace and R.W. Neu: Fatigue Fract. Engng Mater. Struct., Vol. 26 (2003), p. 199.

[32] D.B. Garcia and A.F. Grandt, Jr.: Engng Failure Anal., Vol. 12 (2005), p. 537.

[33] N.R. Lovrich and R.W. Neu: Fatigue Fract. Engng Mater. Struct., Vol. 29 (2006), p. 41.

[34] N.R. Lovrich, X. Huang and R.W. Neu, in: proc. 9th International Fatigue Congress, Atlanta, Georgia, USA, 14-19 May (2006).

[35] C.D. Lykins, S. Mall and V. Jain: Int. J. Fatigue, Vol. 22 (2000), p. 703.

[36] A. Krgo, A.R. Kallmeyer and P. Kurath, in: proc. High Cycle Fatigue, Chandler, AZ (2000).

[37] C.D. Lykins, S. Mall and V. Jain: Fatigue Fract. Engng Mater. Struct., Vol. 24 (2001), p. 461.

[38] H. Lee, O. Jin and S. Mall: Int. J. Fatigue, Vol. 26 (2004), p. 393.

[39] S.A. Namjoshi, S. Mall, V.K. Jain and O. Jin: Fatigue Fract. Engng Mater. Struct., Vol. 25 (2002), p. 955.

[40] A. Fatemi and P. Kurath: J. Engng Mater. Technol., Vol. 110 (1988), p. 380.

[41] A. Fatemi and D.F. Socie: Fatigue Fract. Engng Mater. Struct., Vol. 11 (1988), p. 149.

[42] W.N. Findley: Journal of Engineering for Industry, Vol. B81 (1959), p. 301.

[43] K.N. Smith, P. Watson and T.H. Topper: J. of Materials, Vol. 5(4) (1970), p. 767.

[44] M.P. Szolwinski, J.F. Matlik and T.N. Farris: Int. J. Fatigue, Vol. 21 (1999), p. 671.

[45] C.D. Lykins, S. Mall and V.K. Jain: Int. J. Fatigue, Vol. 23 (2001), p. 703. 
[46] R.W. Neu, J.A. Pape and D.R. Swalla, in: Fretting Fatigue: Current Technology and Practices, ASTM STP 1367, edited by D.W. Hoeppner, V. Chandrasekaran and C.B. Elliott, American Society for Testing and Materials (2000), p. 369.

[47] A.L. Hutson, T. Nicholas, S.E. Olson and N.E. Ashbaugh: Int. J. Fatigue, Vol. 23 Supplement 1 (2001), p. S445.

[48] J.A. Araujo, D. Nowell and R.C. Vivacqua: Fatigue Fract. Engng Mater. Struct., Vol. 27 (2004), p. 967.

[49] D.R. Swalla and R.W. Neu, in: Fretting Fatigue: Advances in Basic Understanding and Applications, ASTM STP 1425, edited by Y. Mutoh, S.E. Kinyon and D.W. Hoeppner, ASTM International, West Conshohocken, PA (2003), p. 89.

[50] S. Naboulsi and S. Mall: Tribol. Int., Vol. 36 (2003), p. 121.

[51] S. Fouvry, P. Duo and P. Perruchaut: Wear, Vol. 257 (2004), p. 916.

[52] J.A. Araujo, L. Susmel, D. Taylor, J.C.T. Ferro and E.N. Mamiya: Int. J. Fatigue, Vol. 29 (2007), p. 95.

[53] O. Jin, J.R. Calcaterra and S. Mall: J.ASTM Int., Vol. 3(7) (2006).

[54] A.E. Giannakopoulos, T.C. Lindley and S. Suresh: Acta Mater., Vol. 46 (1998), p. 2955.

[55] T. Hattori, M. Nakamura and T. Watanabe: Tribol. Int., Vol. 36 (2003), p. 87.

[56] B.P. Conner, T.C. Lindley, T. Nicholas and S. Suresh: Int. J. Fatigue, Vol. 26 (2004), p. 511.

[57] D. Nowell, D. Dini and D.A. Hills: Engng Fract. Mech., Vol. 73 (2006), p. 207.

[58] A. Kapoor: Fatigue Fract. Engng Mater. Struct., Vol. 17 (1994), p. 201.

[59] D.R. Swalla and R.W. Neu: Tribol. Int., Vol. 34 (2001), p. 493.

[60] K. Iyer and S. Mall: J. Engng Mater. Technol., Vol. 123 (2001), p. 85.

[61] S. Naboulsi and T. Nicholas: Int. J. Solids Struct., Vol. 40 (2003), p. 6497.

[62] K. Iyer and S. Mall: Fatigue Fract. Engng Mater. Struct., Vol. 23 (2000), p. 335.

[63] O. Jin and S. Mall: Met. Mater. Trans. A, Vol. 35A (2004), p. 131.

[64] T. Nicholas: High Cycle Fatigue: A Mechanics of Materials Perspective (Elsevier Science, 2006).

[65] T. Nicholas, A.L. Hutson, R. John and S. Olson: Int. J. Fatigue, Vol. 25 (2003), p. 1069.

[66] A.L. Hutson, T. Nicholas and R. John: Int. J. Fatigue, Vol. 27 (2005), p. 1582.

[67] K.S. Chan, Y.-D. Lee, D.L. Davidson and S.J. Hudak, Jr.: Int. J. Fracture, Vol. 112 (2001), p. 299.

[68] K.S. Chan, D.L. Davidson, T.E. Owen, Y.-D. Lee and S.J. Hudak, Jr.: Int. J. Fracture, Vol. 112 (2001), p. 331.

[69] D.B. Garcia and A.F. Grandt: Int. J. Fatigue, Vol. 29 (2007), p. 1311.

[70] R.O. Ritchie, D.L. Davidson, B.L. Boyce, J.P. Campbell and O. Roder: Fatigue Fract. Engng Mater. Struct., Vol. 22 (1999), p. 621.

[71] P.J. Golden, B.B. Bartha, A.F. Grandt, Jr. and T. Nicholas: Int. J. Fatigue, Vol. 26 (2004), p. 281.

[72] K.J. Miller: J. Marine Design Operations, Vol. B7 (2004), p. 11.

[73] M.J. Donachie: Titanium, A Technical Guide (ASM International, Metals Park, Ohio 1988).

[74] M. Zhang, D.L. McDowell and R.W. Neu: submitted to Tribol. Int. (2007).

[75] S. Mall, S.A. Namjoshi and W.J. Porter: Mater. Sci. Engng A, Vol. 383 (2004), p. 334.

[76] J.A. Hines and G. Lütjering: Fatigue Fract. Engng Mater. Struct., Vol. 22 (1999), p. 657.

[77] M.R. Bache, W.J. Evans, B. Suddell and F.R.M. Herrouin: Int. J. Fatigue, Vol. 23 Supplement 1 (2001), p. S153.

[78] F. Bridier, P. Villechaise and J. Mendez, in: proc. 9th International Fatigue Congress, Atlanta, Georgia, USA, 14-19 May (2006).

[79] J.R. Mayeur: M.S. Thesis, Georgia Institute of Technology (2004).

[80] T. Dick and G. Cailletaud: Comp. Mater. Sci., (2006), in press.

[81] T. Dick, C. Paulin, G. Cailletaud and S. Fouvry: Tribol. Int., (2006), in press.

[82] J.R. Mayeur and D.L. McDowell: Int. J. Plasticity (2007), in press.

[83] M.M. Hamdy and R.B. Waterhouse: Wear, Vol. 56 (1979), p. 1. 
[84] O. Jin, S. Mall and O. Sahan: Int. J. Fatigue, Vol. 27 (2005), p. 395.

[85] H. Lee and S. Mall: J. ASTM Int., Vol. 2 (2005), p. 31.

[86] R.B. Waterhouse and A. Iwabuchi: Wear, Vol. 106 (1985), p. 303.

[87] M.H. Wharton and R.B. Waterhouse: Wear, Vol. 62 (1980), p. 287.

[88] M. Peters, A. Gysler and G. Lütjering: Met. Trans. A, Vol. 15A (1984), p. 1597.

[89] L.C. Lietch, H. Lee and S. Mall: Mater. Sci. Engng A, Vol. 403 (2005), p. 281.

[90] H. Lee, S. Mall and W.Y. Allen: Mater. Sci. Engng A, Vol. 420 (2006), p. 72.

[91] P.D. Nicolaou, E.B. Shell and T.E. Matikas: Mater. Sci. Engng A, Vol. A269 (1999), p. 98.

[92] D.R. Swalla, R.W. Neu and D.L. McDowell: J. Tribol., Vol. 126 (2004), p. 809.

[93] D.R. Swalla and R.W. Neu: Tribol. Int., Vol. 39 (2006), p. 1016.

[94] S. Fayeulle, P. Blanchard and L. Vincent: Tribol. Trans., Vol. 36 (1993), p. 267.

[95] T.E. Matikas, E. Shell and P.D. Nicolaou: Proc. of SPIE, Vol. 3585 (1999), p. 2.

[96] E. Sauger, S. Fouvry, L. Ponsonnet, P. Kapsa, J.M. Martin and L. Vincent: Wear, Vol. 245 (2000), p.

[97] R.B. Waterhouse, in: Fretting Fatigue: Current Technology and Practices, ASTM STP 1367 , edited by D.W. Hoeppner, V. Chandrasekaran and C.B. Elliott, American Society for Testing and Materials, West Conshohocken, PA (2000), p. 3.

[98] S.A. Martinez, S. Sathish, M.P. Blodgett, S. Mall and S.A. Namjoshi: Mater. Sci. Engng A, Vol. 399 (2005), p. 58.

[99] S.A. Martinez, S. Sathish, S. Mall and M.P. Blodgett: Met. Mater. Trans. A, Vol. 36A (2005), p. 3385.

[100] A.L. Hutson, S. Sathish and T. Nicholas: Tribol. Int., Vol. 39 (2006), p. 1197.

[101] R. Moobola, D. Nowell and D.A. Hills, in: Engineering Against Fatigue, edited by J.H. Beynon, M.W. Brown, T.C. Lindley, R.A. Smith and B. Tomkins, Balkema, Rotterdam (1999), p. 453.

[102] A.L. Hutson, H. Lee and S. Mall: Tribol. Int., Vol. 39 (2006), p. 1187.

[103] T. Hattori, M. Nakamura and T. Ishizuka, in: Standardization of Fretting Fatigue Test Methods and Equipment, ASTM STP 1159, edited by M.H. Attia and R.B. Waterhouse, American Socieity for Testing and Materials, Philadelphia (1992), p. 101.

[104] H. Proudhon, S. Fouvry and J.-Y. Buffiere: Int. J. Fatigue, Vol. 27 (2005), p. 569.

[105] C. Lutynski, G. Simansky and A.J. McEvily, in: Materials Evaluation Under Fretting Conditions, ASTM STP 780, American Society for Testing and Materials, (1982), p. 150.

[106] H. Lee, O. Jin and S. Mall: Fatigue Fract. Engng Mater. Struct., Vol. 26 (2003), p. 767.

[107] S.A. Namjoshi, V.K. Jain and S. Mall: J. Engng Mater. Technol., Vol. 124 (2002), p. 222.

[108] M.J. Shepard, P.S. Prevéy and N. Jayaraman, in: proc. 8th National Turbine Engine High Cycle Fatigue (HCF) Conference, Monterey, CA, April 14-16 (2003).

[109] V. Sabelkin, S.A. Martinez, S. Mall, S. Sathish and M.P. Blodgett: Fatigue Fract. Engng Mater. Struct., Vol. 28 (2005), p. 321.

[110] A. King, A.D. Evans, P.J. Withers and C. Woodward: Materials Science Forum, Vol. 490491 (2005), p. 340.

[111] P.J. Golden, A.L. Hutson, V. Sundaram and J.H. Arps: Int. J. Fatigue, Vol. 29 (2007), p. 1302.

[112] P.S. Prevéy, R.A. Ravindranath, M.J. Shepard and T.P. Gabb: J. Engng Gas Turbines Power, Vol. 128 (2006), p. 865.

[113] P.J. Golden and M.J. Shepard: Mater. Sci. Eng. A, Vol. 468-470 (2007), p. 15.

[114] B.P. Conner and T. Nicholas: J. Engng Mater. Technol., Vol. 128 (2006), p. 133.

[115] H. Soyama, D.O. Macodiyo and S. Mall: Tribol. Let., Vol. 17 (2004), p. 501.

[116] S. Shkarayev and S. Mall: J. Strain Anal., Vol. 38 (2003), p. 495.

[117] A.M. Korsunsky, K. Kim, M. Golshan and G.M. Regino: Materials Science Forum, Vol. 524-525 (2006), p. 343.

[118] J.A. Collins and F.M. Tovey: J. Materials, Vol. 7 (1972), p. 460.

[119] H. Lee, S. Sathish and S. Mall: J. Mater. Sci., Vol. 39 (2004), p. 7089. 
[120] H. Lee and S. Mall: Mater. Sci. Engng, Vol. A366 (2004), p. 412.

[121] H. Lee, S. Mall and S. Sathish: Mater. Sci. Engng A, Vol. 390 (2005), p. 227.

[122] R.G. Vardiman, D. Creighton, G. Saliver, A. Effatian and B.B. Rath: Chem. Technol. Rev. (1983), p. 165.

[123] S. Saritas, R.P.M. Procter and W.A. Grant: Mater. Sci. Engng A, Vol. 115 (1989), p. 307.

[124] J.E. Elder, R. Thamburaj and P.C. Patnaik: Surf. Engng, Vol. 5 (1989), p. 55.

[125] J.E. Barry, E.J. Tobin and P. Sioshansi: Surf. Coat. Technol., Vol. 31 (1992), p. 176.

[126] A. Vadiraj, M. Kamaraj, U.K. Mudali and A.K. Nath: Mater. Sci. Technol., Vol. 22 (2006), p. 1119.

[127] N.C. Horswill, K. Sridharan and J.R. Conrad: J. Mater. Sci. Let., Vol. 14 (1995), p. 1349.

[128] A. Vadiraj and M. Kamaraj: Tribol. Int., Vol. 40 (2007), p. 82.

[129] A. Vadiraj and M. Kamaraj: J. Mater. Engng Perform., Vol. 15 (2006), p. 553.

[130] Y. Fu, N.L. Loh, A.W. Batchelor, D. Liu, X. Zhu, J. He and K. Xu: Surf. Coat. Technol., Vol. 106 (1998), p. 193.

[131] W. Ren, S. Mall, J.H. Sanders and S.K. Sharma: Tribol. Trans., Vol. 46 (2003), p. 353.

[132] O. Jin, S. Mall, J.H. Sanders and S.K. Sharma: Surf. Coat. Technol., Vol. 201 (2006), p. 1704.

[133] W. Ren, S. Mall, J.H. Sanders and S.K. Sharma: Surf. Coat. Technol., Vol. 192 (2005), p. 177.

[134] H. Lee, S. Mall, J.H. Sanders and S.K. Sharma: Tribol. Let., Vol. 19 (2005), p. 239.

[135] H. Lee, S. Mall, J.H. Sanders, S.K. Sharma and R.S. Magaziner: Tribol. Int., Vol. 40 (2007), p. 1301.

[136] A.L. Hutson, M. Niinomi, T. Nicholas and D. Eylon: Int. J. Fatigue, Vol. 24 (2002), p. 1223.

[137] M. Niinomi, A.L. Hutson, E.B. Shell, D. Eylon and T. Nicholas: Mater. Sci. Forum, Vol. 426 (2003), p. 649.

[138] H. Proudhon, J.-Y. Buffiere and S. Fouvry: Engng Fract. Mech., Vol. 74 (2007), p. 782. 